\title{
The Use of Big Data and its Effects on the Right to Privacy: A Sharī'ah Perspective
}

\author{
Ahmad Badri Abdullah*
}

The use of big data systems is expanding faster than the rules or legal infrastructures that manage them. Everyday, transnational companies like Google process more than 24,000 terabytes of data and a few largest banks in the world manage more than 75 terabytes of internal corporate data. Facebook, the parallel world with 1.2 billion users at a time who send 10 billion messages, upload 350 million pictures and 250 million videos, is another hallmark of the rise of big data.

TechAmerica Foundation sees big data as characterised by three main factors: volume, velocity and variety. In other words, big data is the perpetual growing culmination of datasets derived from different sources to be analysed and mined in a manner which traditional database technologies are not capable of. It requires powerful computing facilities to filter massive amount of information so as to determine trends and behavioral patterns in the pursuit of making smarter and more accurate decisions.

To date, the use of big data is everywhere. This is evident as entertainment companies are creating television series based on their costumer's specific preferences, and data brokers collect employment information and sell them to debt collectors, financial institutions, and the like. With the ability to access unimaginable amount of data, business organisations may gain valuable insights with which their operations and earnings could be significantly improved. It is interesting to note the user of big data by a retailer such as Target is able to determine the time that its costumers get pregnant, by analysing their purchasing history and sending them online marketing materials early on to win business. A similar case applies to Amazon and Netflix who recommend products based upon the costumers' purchasing history. Furthermore, the use of big data is forecasted eventually to help in finding the cure for cancer and other chronic diseases. In sum, the societal benefit (mașlahah) that is presented by the use of big data is indubitably enormous. Nonetheless, as big data becomes more widely utilised, the legal risks and ethical issues associates with it also become more of a concern.

Issues and risks regarding the use of big data are typically sidelined since organisations that resort to such practices merely focus on enhancing their business efficiency and profits. This in turn has resulted in the drowning out of the calls for risk oversight. Bernard Marr in his article suggests that the crux of the problem lies in the fact that most data collection and analysis is not done transparently since the extent to which data is analysed and mined is not disclosed. Given 
that, the most significant legal challenge associated with big data is privacy. For instance, personal information may end up in the database of a data broker, being combined and disclosed in ways that do not comply with any privacy policy. If an e-commerce vendor informed a marketer that a person purchased a deep fryer, such information could find its way into a data broker's database. If the broker then sells access to the database to a health insurance company whose algorithm deems a person who likes deep fries as exposed to high risk, an initial innocuous data disclosure may end up serving as the basis for denying a person from accessing health care facilities and services. Furthermore, in most cases data subjects do not know what entities are collecting information about them, particularly by the data brokers. Data subjects do not have direct access to them and these brokers do not receive information directly from the data subjects. All this may expose data subjects to the risk of their personal information being misused by unknown parties.

An important requirement of privacy is that a person is able to keep certain information about himself concealed and inaccessible to others. Islam in this matter guarantees the sanctity of private life because it prohibits prying into people's personal affairs or disseminating personal information. The Qur'an admonishes against the act of prying into other's personal realms as well as any measures of disseminating such information:

O you who have attained to faith! Avoid most guesswork [about one another] for, behold, some of [such] guesswork is [in itself] a sin; and do not spy upon one another, and neither allow yourselves to speak ill of one another behind your backs. Would any of you like to eat the flesh of his dead brother? Nay, you would loathe it! And be conscious of God. Verily, God is an acceptor of repentance, a dispenser of grace (Q, Al-Ḥujurāt, 49: 18).

Indeed, those who like that immorality should be spread [or publicized] among those who have believed will have a painful punishment in this world and the Hereafter. And Allah knows and you do not know (Q, An-Nūr, 24: 12).

Kamali points out that the right to privacy in Islam not only refers to the sanctity of an individual's home but to all other aspects of privacy that range from personal correspondence, the confidentiality of one's private activities, personal conversation to financial affairs. Therefore, in the pursuit of protecting the sanctity of the private sphere, measures to protect the privacy of data subjects need to be given due consideration. The technique for mitigating privacyrelated risk of big data is the de-identification or anonymisation of data sets. 
Such technique strips away key information from data sets so as to prevent other parties from identifying to whom the data sets might refer. Nevertheless, if the de-identification process is not done properly, data that appeared anonymous could be re-identified and there have been several real-life events in which reidentification of data sets has occurred. However, David Nevetta suggests that with the abundance of data available and accessible with sophisticated algorithms that allow data-mining, true anonymisation is actually more difficult to achieve.

Personal autonomy is among the most important ethical requirements that are based on the idea that every individual owns the intrinsic right to make informed decisions. Islam acknowledges the concept of autonomy since God created man as his viceroy on earth and endowed them with honor. Therefore Islamic jurisprudence rules that no one is entitled to dispose of the right of a human being without his consent and permission. However, in the case of big data usage, data subjects often lack understanding of the interpretations, inferences, and deductions processes which are made and drawn from his combined data through the big data mining techniques and analysis, and therefore have little ability to provide consent.

Another alarming matter pertaining to the use of big data that triggers Shari 'ah issues is the 'predictive policing and punishment'. A growing number of places in the United States, ranging from Los Angeles, Richmond to Virginia are currently employing the use of big data analysis to select groups and individuals to subject to extra scrutiny simply due to an algorithm that suggests them as more likely to commit crime. Such systems seek to prevent crimes by predicting who might commit them. The fundamental setback of such a system is that it negates the foundational principle of justice in the Sharī 'ah - the presumption of innocence since it holds people responsible for what their prediction indicates they are likely to do. With such a system society might be safer, however only at the expense of the ability to make choices and being held responsible for them. Individuals in the system are denied their ability to make moral choices.

In summing up, we need to weigh cautiously the benefit (maslahah) and harm (mafsadah) implied by the use of big data. Of course big data offers numerous benefits. However, it could also turn out to be dehumanising due to the ways in which it is being utilised. The misuse of big data necessitates protection and preventive measures, be it in the form of laws or public policies. Nonetheless laws and policies are not quite sufficient to deal with such a complex subject. More importantly, the use of big data by Muslim entrepreneurs data brokers needs to be governed by Islamic ethical principles, which are underpinned by the higher objectives of Sharì ah. 


\section{Notes}

* Ahmad Badri bin Abdullah is Research Fellow at IAIS Malaysia (Email: badri@ iais.org.my).

\section{References}

Bernard Marr, Big Data: Using SMART Big Data, Analytics and Metrics to Make Better Decisions and Improve Performance, (USA, John Wiley \& Sons Inc., 2015).

David Navetta, "Legal Implication of Big Data: A Primer" in Information Systems Security Association Journal, no.14, (March 2013).

Gamil Muhammed Hussein, "Basic Guarantees In Islamic Criminal Justice System" in Criminal Justice in Islam: Judicial Procedure in the Shari'ah, M. Abdel Haleem, Adel Omar Sharif, Kate Daniels (edit), (New York, I.B. Tauris, 2003)

Mohammad Hashim Kamali, The Right to Life, Security, Privacy and Ownership in Islam, (Kuala Lumpur: IAIS Malaysia \& Ilmiah Publisher, 2013).

Viktor Mayer-Schonberger \& Kenneth Cukier, Big Data: A Revolution That Will Transform How We Live, Work \& Think, (London: John Murray (Publishers), 2013). 